University of Nebraska - Lincoln

DigitalCommons@University of Nebraska - Lincoln

Publications, Agencies and Staff of the U.S.

Department of Commerce

U.S. Department of Commerce

2003

\title{
A MODEL LIFE TABLE FOR BOTTLENOSE DOLPHINS (TURSIOPS TRUNCATUS) FROM THE INDIAN RIVER LAGOON SYSTEM, FLORIDA, U.S.A.
}

Megan K. Stolen

University of Central Florida, mstolen@hswri.org

Jay Barlow

National Marine Fisheries Service, jay.barlow@noaa.gov

Follow this and additional works at: https://digitalcommons.unl.edu/usdeptcommercepub

Part of the Environmental Sciences Commons

Stolen, Megan K. and Barlow, Jay, "A MODEL LIFE TABLE FOR BOTTLENOSE DOLPHINS (TURSIOPS TRUNCATUS) FROM THE INDIAN RIVER LAGOON SYSTEM, FLORIDA, U.S.A." (2003). Publications, Agencies and Staff of the U.S. Department of Commerce. 317.

https://digitalcommons.unl.edu/usdeptcommercepub/317

This Article is brought to you for free and open access by the U.S. Department of Commerce at DigitalCommons@University of Nebraska - Lincoln. It has been accepted for inclusion in Publications, Agencies and Staff of the U.S. Department of Commerce by an authorized administrator of DigitalCommons@University of Nebraska - Lincoln. 


\title{
A MODEL LIFE TABLE FOR BOTTLENOSE DOLPHINS (TURSIOPS TRUNCATUS) FROM THE INDIAN RIVER LAGOON SYSTEM, FLORIDA, U.S.A.
}

\author{
Megan K. StOlen ${ }^{1}$ \\ University of Central Florida, \\ Department of Biology, \\ 4000 Central Florida Boulevard, \\ Orlando, Florida 32816-2368, U.S.A. \\ E-mail: mstolen@hswri.org \\ JAY BARLOW \\ National Marine Fisheries Service, \\ Southwest Fisheries Science Center, \\ 8604 La Jolla Shores Drive, \\ La Jolla, California 92037, U.S.A.
}

\begin{abstract}
Data gathered from 220 stranded bottlenose dolphins (Tursiops truncatus) in the Indian River Lagoon system, Florida, were used to derive a life table. Survivorship curves were fit to the data using Siler's competing-risk model and a maximum likelihood approach. Population growth was estimated to be between $r=0.0$ and 0.046 based on the observed numbers of stranded dolphins. Variance in survival rates was estimated using an individual-based, age-structured population projection model. We estimate that the overall annual mortality rate for this population was $9.8 \%$ per year. Sex-specific differences in survivorship were apparent with females outliving males. The overall mortality curve resembles that of other large mammals, with high calf mortality and an exponentially increasing risk of senescent mortality. The inclusion of live-capture removals of individuals from this population did not significantly affect the estimation of survival parameters for most age classes.
\end{abstract}

Key words: life table, demography, mortality, survival, bottlenose dolphin, Tursiops, life history, survivorship, population growth, longevity.

Baseline mortality data are important in understanding many aspects of marine mammal life history. Long-term monitoring of mortality is valuable in detecting

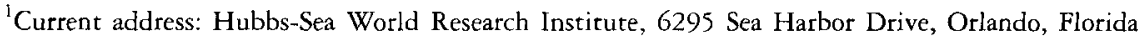
32821-8043, U.S.A.
} 
unusual mortality events (Aguilar and Raga 1993, Duignan et al. 1996, Vidal and Gallo-Reynoso 1996) and increases in mortality due to fisheries or other human causes (Nieri et al. 1999, Bodkin et al. 2000). Mortality data are valuable for modeling the viability of endangered and threatened species by estimating vital rates or the effects of extrinsic factors on the health of the population. A life table is a vector of age-specific survival or mortality rates, and represents an important tool for understanding the demography of populations. Life tables have proven to be extremely powerful tools for conservation when coupled with models that predict susceptibility of age classes to anthropogenic effects (e.g., Crouse et al. 1987, Doak et al. 1994).

Survivorship and mortality can be inferred directly by following one or more cohorts through time, or indirectly from analysis of an age distribution of living individuals (Caughley 1966, Barlow and Boveng 1991) or from the age distribution of deaths (Caughley 1966, Spinage 1972). Each method involves restrictive assumptions that are unlikely to be met exactly but are often approximated well enough for practical purposes. Life tables based on age-at-death data, and the mortality and survival curves that are derived from them, have been produced for several species of large mammals such as hippopotamus (Laws 1968), African buffalo (Sinclair 1977), Himalayan thar, Dall's sheep (see review in Caughley 1966), impala, zebra, and warthogs (see review in Spinage 1972). Several of these have utilized carcasses, skulls, or similar artifacts to determine the ages of the animals (Laws 1968, Spinage 1972, Sinclair 1977).

Published examples of life tables for marine mammals are scarce (Barlow and Boveng 1991). A few have been developed for pinnipeds and sea otters (Hewer 1964, Barlow and Boveng 1991, Siniff and Ralls 1991, Clinton and Le Boeuf 1993). In sirenians, a detailed life table was calculated for female Florida manatees by Marmontel (1993) and was used to predict long-term viability of this endangered species (Marmontel et al. 1997). In cetaceans, mortality models based on life stages have been constructed (Brault and Caswell 1993, Barlow and Clapham 1997); however, detailed age-structured life tables (e.g., Olesiuk et al. 1990) are extremely rare.

We present a life table for bottlenose dolphins from the Indian River Lagoon system (IRL), Florida, using data from stranded animals. While data on residency patterns of IRL dolphins are relatively scarce, there is evidence that at least some of the dolphins are year-round residents of the system. Some dolphins that were captured and freeze-branded in the lagoon from 1979 to 1981 (Odell and Asper 1990) are still occasionally sighted inside the system (M. Stolen, personal observation). There is some evidence from aerial surveys (Scott 1990) and seasonal stranding trends (Stolen 1998) of a summer influx and autumn efflux of dolphins from the river system. We do not have sufficient movement pattern data on IRL dolphins to determine how many dolphins, if any, are moving into and out of the IRL system boundaries. If the dolphins are using both habitats, our study is based on the assumption that age specific mortality within the lagoon is the same as that experienced by our population outside the lagoon.

Data and biological samples from stranded carcasses within the IRL have been systematically gathered since 1978 and provide an accurate source of life history information for this population (Hersh et al. 1990, Stolen 1998). Our life table relies on age-at-death data using teeth gathered from carcasses for age estimation. We fit a smooth age-specific survivorship function (Siler 1979) to these mortality data using a maximum likelihood method. The resulting life table provides 
parameters that will be useful for more-detailed demographic modeling of bottlenose dolphins, and the approach could be applied to other groups for which mortality data are available.

\section{METHODS}

\section{Age Estimation}

Reports of dead bottlenose dolphins have been regularly collected in the Indian River Lagoon since 1978. The IRL is a shallow-water estuarine system along the east coast of Florida that covers a linear distance of $c a .225 \mathrm{~km}$ (Fig. 1). Standard stranding data were gathered by members of the Southeastern United States Stranding Network and included the following information: sex, total length, location, and date of stranding. Sex was determined by external and internal examination. In 220 cases (of 491 strandings) from 1978 to 1997, teeth were available for age estimation. Teeth were processed using standard decalcification and staining methods (Myrick et al. 1983, Hohn et al, 1989). Each tooth was cut into a $2-\mathrm{mm}$ section using a low speed saw, fixed in $10 \%$ formalin for $24 \mathrm{~h}$, and rinsed in running tap water for $3 \mathrm{~h}$. Sections were then decalcified in RDO (a commercially available mixture of acids, Apex Engineering Products Corp., Plainfield, IL) and rinsed again in tap water for $6 \mathrm{~h}$. Decalcified teeth were sectioned using a sledge-type microtome with freezing attachment, and stained with Mayer's hematoxylin. Stained sections were blued in weak ammonia solution and mounted in glycerin onto slides.

Sections were examined for growth layer groups (GLGs) as defined by Perrin and Myrick (1980) and Hohn et al. (1989) in both dentine and cementum. A GLG is equal to an annual layer in this species (Sergeant et al. 1973, Hohn et al. 1989). Sections were examined using a stereoscopic microscope under $10 \times-60 \times$ with transmitted light. Finer layers were also examined with a compound microscope under higher magnification. Sections were read blindly by one author (MKS) three times using the model developed for Tursiops teeth by Hohn et al. (1989). If two of three readings were the same, that number was used as the age estimate. Small discrepancies (one or two growth layers difference between any of the readings) were resolved by a fourth reading. Larger discrepancies were resolved by repetition of the procedure with an additional tooth sample. Dolphins were placed into age classes by rounding ages to the last fully-formed GLG.

\section{Survivorship, Mortality Rates, and Life Tables}

Age-specific survivorship and mortality rates were estimated by fitting the Siler competing-risk model to these age-at-death data. This model was used because it adequately fits the expected mortality patterns for a wide range of long-lived species (Siler 1979, Gage and Dyke 1988, Barlow and Boveng 1991). Survivorship to age $x$ is given as the product of three competing risks,

$$
l(x)=l_{j}(x) \cdot l_{c}(x) \cdot l_{s}(x)
$$

a constant risk experienced by all age classes, 


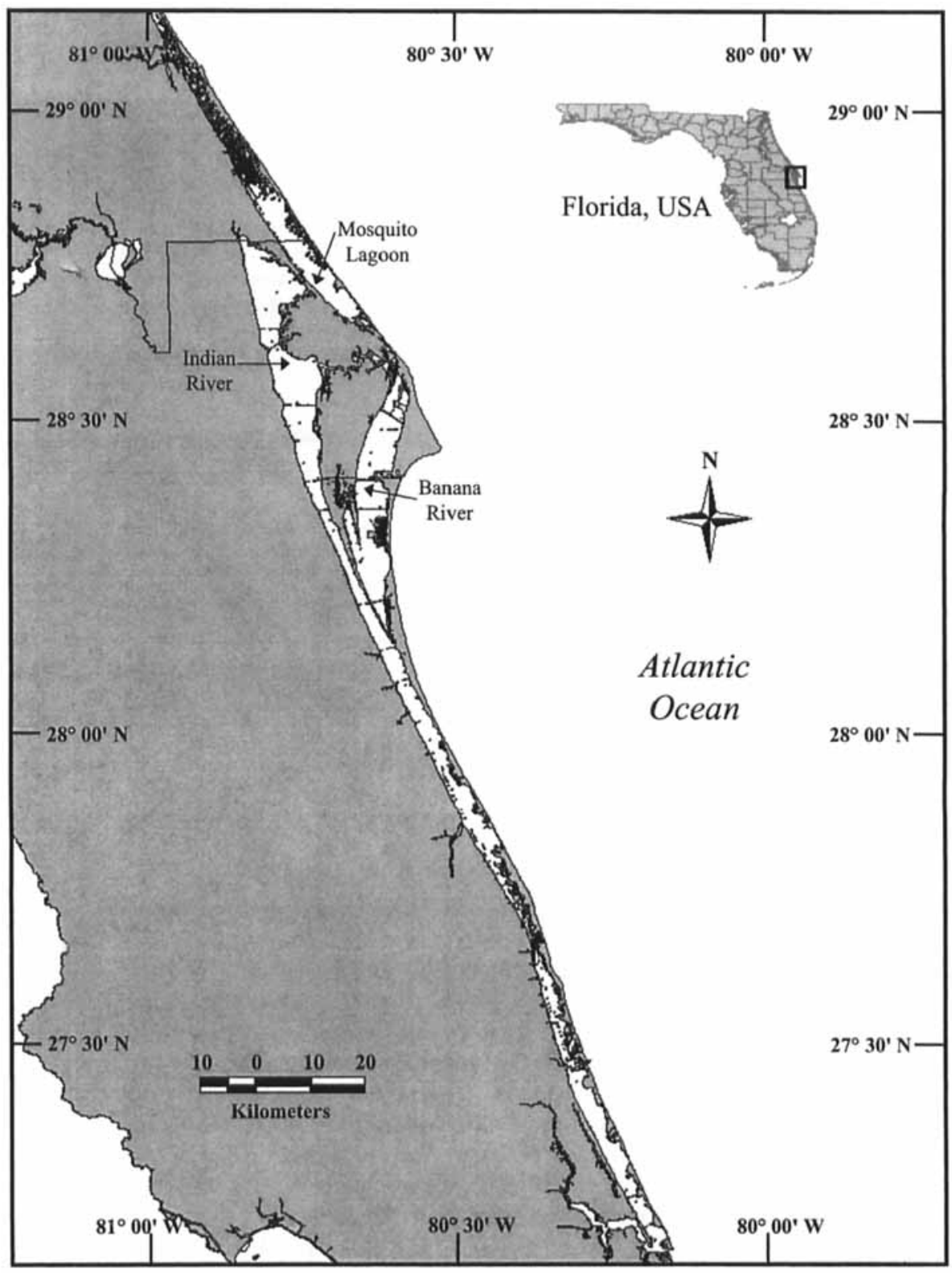

Figure 1. Map of the study area (Indian River Lagoon system) along the central east coast of Florida.

$$
l_{c}(x)=\exp \left\{-a_{2} \cdot x\right\}
$$

an exponentially decreasing risk due to juvenile risk factors,

$$
l_{j}(x)=\exp \left\{\left(-a_{1} / b_{1}\right) \cdot\left[1-\exp \left(-b_{1} \cdot x\right)\right]\right\},
$$

and an exponentially increasing risk due to senescent risk factors, 


$$
l_{s}(x)=\exp \left\{\left(a_{3} / b_{3}\right) \cdot\left[1-\exp \left(b_{3} \cdot x\right)\right]\right\}
$$

Discrete, age-specific survival rates $\left(p_{x}\right)$ and mortality rates $\left(q_{x}\right)$ may be calculated from this continuous survivorship function as,

$$
p_{x}=\left(1-q_{x}\right)=l(x+1) / l(x)
$$

For a population in stable age distribution and growing at an exponential rate $r$, the number dying in each age class $\left(d_{x}\right)$ will be proportional to the number of individuals in that age class times the mortality rate for that age class

$$
d_{x} \propto\left[e^{-r x} \cdot l(x)\right] \cdot q_{x}
$$

Therefore, by combining Eq. 2 and 3, the probability that a given mortality will be in age class $x$ is

$$
\operatorname{Pr}(x)=\frac{e^{-r x}[l(x)-l(x+1)]}{\sum_{y=0}^{w}\left\{e^{-r y}[l(y)-l(y+1)]\right\}},
$$

where $w$ is the maximum age class. The likelihood of an observed age-at-death distribution is therefore

$$
L(\mathbf{n})=\prod_{x=0}^{w}[\operatorname{Pr}(x)]^{n_{x}}
$$

where $n_{x}=$ number of deaths observed at age $x$, and $\mathrm{n}=$ vector of $n_{x}$.

The five Siler parameters were estimated to fit the observed distribution of agesat-death by maximizing the logarithm of this likelihood function using the simplex algorithm (Press et al. 1988). We considered two values for population growth rate: based on trends in stranding rates $(r=0.046)$ and based on a stable population $(r=0.0)$. To estimate the growth rate from trends in stranding rate, we assume that age-specific birth and death rates and the proportion of strandings that are reported do not change. Under those assumptions, an increase in population size would be accompanied by a proportional increase in the observed stranding rate. We estimated population growth rate, $r$, by regressing the natural logarithm of the number of strandings per year against year. For comparison to this new approach (model fitting with maximum likelihood), we also calculated a life table using the traditional method described by Krebs (1989). Traditional life tables (Table 1-3) were constructed using estimated ages and based on a hypothetical cohort of 1,000 dolphins where $n_{x}$ is the number of dolphins alive at age $x, d_{x}$ is the number dying within age interval $x$ to $x+1, l_{x}$ is the proportion surviving at the start of age $x$, and $q_{x}$ is the mortality rate (Krebs 1989). These life table calculations were based on the assumptions that carcass recovery and tooth collection were independent of the age and sex of IRL dolphins and that the population has a stable age distribution and a zero growth rate (together termed a stationary age distribution per Caughley 1966). These calculations are limited to the case where population growth rate is zero, but this method has the advantage of not using a particular parametric model and thus can show more detail in age-specific variations. 
Table 1. Life table for both sexes of bottlenose dolphins of the Indian River Lagoon systems based on stranded animals from 1978 to $1997(n=220)$. Life table parameters are calculated using the traditional method as given by Krebs (1989), where $n_{x}=$ number alive at age $x, d_{x}=$ the number dying within age interval $x$ to $x+1, l_{x}=$ the proportion surviving at start of age $x$, and $q_{x}=$ the mortality rare.

\begin{tabular}{|c|c|c|c|c|c|c|}
\hline Age class $(x)$ & \# dolphins & $\%$ of total & $n_{x}$ & $d_{x}$ & $l_{x}$ & $q x$ \\
\hline 0 & 36 & 16.36 & 1,000 & 164 & 1.000 & 0.164 \\
\hline 1 & 14 & 6.36 & 836 & 64 & 0.836 & 0.076 \\
\hline 2 & 32 & 14.55 & 773 & 145 & 0.773 & 0.188 \\
\hline 3 & 15 & 6.82 & 627 & 68 & 0.627 & 0.109 \\
\hline 4 & 13 & 5.91 & 559 & 59 & 0.559 & 0.106 \\
\hline 5 & 8 & 3.64 & 500 & 36 & 0.500 & 0.073 \\
\hline 6 & 4 & 1.82 & 464 & 18 & 0.464 & 0.039 \\
\hline 7 & 5 & 2.27 & 445 & 23 & 0.445 & 0.051 \\
\hline 8 & 3 & 1.36 & 423 & 14 & 0.423 & 0.032 \\
\hline 9 & 3 & 1.36 & 409 & 14 & 0.409 & 0.033 \\
\hline 10 & 2 & 0.91 & 395 & 9 & 0.395 & 0.023 \\
\hline 11 & 3 & 1.36 & 386 & 14 & 0.386 & 0.035 \\
\hline 12 & 3 & 1.36 & 373 & 14 & 0.373 & 0.037 \\
\hline 13 & 6 & 2.73 & 359 & 27 & 0.359 & 0.076 \\
\hline 14 & 3 & 1.36 & 332 & 14 & 0.332 & 0.041 \\
\hline 15 & 8 & 3.64 & 318 & 36 & 0.318 & 0.114 \\
\hline 16 & 5 & 2.27 & 282 & 23 & 0.282 & 0.081 \\
\hline 17 & 5 & 2.27 & 259 & 23 & 0.259 & 0.088 \\
\hline 18 & 8 & 3.64 & 236 & 36 & 0.236 & 0.154 \\
\hline 19 & 3 & 1.36 & 200 & 14 & 0.200 & 0.068 \\
\hline 20 & 11 & 5.00 & 186 & 50 & 0.186 & 0.268 \\
\hline 21 & 4 & 1.82 & 136 & 18 & 0.136 & 0.133 \\
\hline 22 & 1 & 0.45 & 118 & 5 & 0.118 & 0.038 \\
\hline 23 & 4 & 1.82 & 114 & 18 & 0.114 & 0.160 \\
\hline 24 & 3 & 1.36 & 95 & 14 & 0.095 & 0.143 \\
\hline 25 & 3 & 1.36 & 82 & 14 & 0.082 & 0.167 \\
\hline 26 & 6 & 2.73 & 68 & 27 & 0.068 & 0.400 \\
\hline 27 & 2 & 0.91 & 41 & 9 & 0.041 & 0.222 \\
\hline 28 & 1 & 0.45 & 32 & 5 & 0.032 & 0.143 \\
\hline 29 & 2 & 0.91 & 27 & 9 & 0.027 & 0.333 \\
\hline 30 & 0 & 0.00 & 18 & 0 & 0.018 & 0.000 \\
\hline 31 & 1 & 0.45 & 18 & 5 & 0.018 & 0.250 \\
\hline 32 & 0 & 0.00 & 14 & 0 & 0.014 & 0.000 \\
\hline 33 & 1 & 0.45 & 14 & 5 & 0.014 & 0.333 \\
\hline 34 & 0 & 0.00 & 9 & 0 & 0.009 & 0.000 \\
\hline 35 & 2 & 0.91 & 9 & 9 & 0.009 & 1.000 \\
\hline
\end{tabular}

\section{Variance in Parameter Estimation}

Variance in parameter estimation comes from random demographic deviations from stable age distributions and from random sampling. To capture both sources of variation, standard deviations and confidence intervals for $l_{x}$ and $q_{x}$ parameters were estimated using an individual-based, age-structured population projection model with full demographic stochasticity and with random sampling of the individuals that die. Male and female individuals in the population were tracked 
Table 2. Life table for male bottlenose dolphins from the Indian River Lagoon system based on stranded animals from 1978 to $1997(n=125)$ where $l_{x}=$ the proportion surviving to age $x, q_{x}=$ the mortality rate calculated using traditional life table methods, and smoothed $q_{x}$ is calculated based on two assumed population growth rates $(r)$ using a maximum-likelihood fit to the Siler model.

\begin{tabular}{|c|c|c|c|c|c|}
\hline Age class $(x)$ & \# of males & $l_{x}$ & $\begin{array}{l}\text { Traditionally } \\
\text { calculated } q_{x}\end{array}$ & $\begin{array}{c}\text { Smoothed } q_{x} \\
r=0.000\end{array}$ & $\begin{array}{c}\text { Smoothed } q_{x} \\
r=0.046\end{array}$ \\
\hline 0 & 22 & 1.000 & 0.176 & 0.176 & 0.114 \\
\hline 1 & 9 & 0.824 & 0.087 & 0.149 & 0.095 \\
\hline 2 & 17 & 0.752 & 0.181 & 0.127 & 0.080 \\
\hline 3 & 10 & 0.616 & 0.130 & 0.110 & 0.069 \\
\hline 4 & 9 & 0.536 & 0.134 & 0.097 & 0.061 \\
\hline 5 & 5 & 0.464 & 0.086 & 0.087 & 0.055 \\
\hline 6 & 4 & 0.424 & 0.075 & 0.081 & 0.051 \\
\hline 7 & 4 & 0.392 & 0.082 & 0.076 & 0.049 \\
\hline 8 & 3 & 0.360 & 0.067 & 0.074 & 0.048 \\
\hline 9 & 0 & 0.336 & 0.000 & 0.073 & 0.048 \\
\hline 10 & 1 & 0.336 & 0.024 & 0.074 & 0.050 \\
\hline 11 & 3 & 0.328 & 0.073 & 0.076 & 0.052 \\
\hline 12 & 1 & 0.304 & 0.026 & 0.079 & 0.056 \\
\hline 13 & 5 & 0.296 & 0.135 & 0.084 & 0.060 \\
\hline 14 & 1 & 0.256 & 0.031 & 0.089 & 0.066 \\
\hline 15 & 7 & 0.248 & 0.226 & 0.096 & 0.072 \\
\hline 16 & 2 & 0.192 & 0.083 & 0.104 & 0.079 \\
\hline 17 & 3 & 0.176 & 0.136 & 0.113 & 0.087 \\
\hline 18 & 4 & 0.152 & 0.211 & 0.123 & 0.096 \\
\hline 19 & 2 & 0.120 & 0.133 & 0.133 & 0.106 \\
\hline 20 & 3 & 0.104 & 0.231 & 0.146 & 0.117 \\
\hline 21 & 1 & 0.080 & 0.100 & 0.159 & 0.130 \\
\hline 22 & 0 & 0.072 & 0.000 & 0.173 & 0.144 \\
\hline 23 & 2 & 0.072 & 0.222 & 0.189 & 0.159 \\
\hline 24 & 2 & 0.056 & 0.286 & 0.206 & 0.176 \\
\hline 25 & 2 & 0.040 & 0.400 & 0.224 & 0.194 \\
\hline 26 & 1 & 0.024 & 0.333 & 0.244 & 0.214 \\
\hline 27 & 1 & 0.016 & 0.500 & 0.265 & 0.235 \\
\hline 28 & 0 & 0.008 & 0.000 & 0.288 & 0.259 \\
\hline 29 & 0 & 0.008 & 0.000 & 0.313 & 0.284 \\
\hline 30 & 0 & 0.008 & 0.000 & 0.339 & 0.312 \\
\hline 31 & 0 & 0.008 & 0.000 & 0.366 & 0.341 \\
\hline 32 & 0 & 0.008 & 0.000 & 0.395 & 0.372 \\
\hline 33 & 0 & 0.008 & 0.000 & 0.425 & 0.405 \\
\hline 34 & 0 & 0.008 & 0.000 & 0.457 & 0.440 \\
\hline 35 & 1 & 0.008 & 1.000 & 0.490 & 0.477 \\
\hline 36 & 0 & & & 0.524 & 0.515 \\
\hline 37 & 0 & & & 0.559 & 0.554 \\
\hline 38 & 0 & & & 0.595 & 0.594 \\
\hline 39 & 0 & & & 0.631 & 0.635 \\
\hline
\end{tabular}

within the model and had different age-specific survival rates (based on the Siler survivorship as estimated above). A population was initiated with $N$ individuals. The numbers of individuals in each age/sex class (stored as integers) were projected through time in one-year time steps. At each time step, each individual faced a 
Table 3. Life table for female bottlenose dolphins from the Indian River Lagoon system based on standard animals from 1978 to $1997(n=78)$ where $l_{x}=$ the proportion surviving to age $x, q_{x}=$ the mortality rate calculated using traditional life table methods, and smoothed $q_{x}$ is calculated based on two assumed population growth rates $(r)$ using a maximumlikelihood method fit to the Siler model. Age specific fecundity rates $\left(m_{x}\right)$ are from a birthinterval model (see text) and were selected to give the indicted population growth rates. Fecundity rates are for a Leslie matrix model and are expressed as the probability that a female age $x$ will survive to the following year and will give birth to a female calf at that time.

\begin{tabular}{|c|c|c|c|c|c|c|c|}
\hline $\begin{array}{l}\text { Age } \\
\text { class } \\
\end{array}$ & $\begin{array}{c}\text { \# of } \\
\text { females }\end{array}$ & $l x$ & $\begin{array}{l}\text { Traditionally } \\
\text { calculated } q_{x}\end{array}$ & $\begin{array}{c}\text { Smoothed } q_{x} \\
r=0.000\end{array}$ & $\begin{array}{c}\text { Smoothed } q_{x} \\
r=0.046\end{array}$ & $\begin{array}{c}m_{x} \\
r=0.000\end{array}$ & $\begin{array}{c}m_{x} \\
r=0.046 \\
\end{array}$ \\
\hline 0 & 10 & 1.00 & 0.128 & 0.158 & 0.082 & 0.000 & 0.000 \\
\hline 1 & 5 & 0.87 & 0.074 & 0.120 & 0.061 & 0.000 & 0.000 \\
\hline 2 & 13 & 0.81 & 0.206 & 0.091 & 0.046 & 0.000 & 0.000 \\
\hline 3 & 4 & 0.64 & 0.080 & 0.070 & 0.035 & 0.000 & 0.000 \\
\hline 4 & 2 & 0.59 & 0.043 & 0.055 & 0.027 & 0.000 & 0.000 \\
\hline 5 & 3 & 0.56 & 0.068 & 0.045 & 0.022 & 0.000 & 0.000 \\
\hline 6 & 0 & 0.53 & 0.000 & 0.038 & 0.019 & 0.000 & 0.000 \\
\hline 7 & 0 & 0.53 & 0.000 & 0.034 & 0.018 & 0.000 & 0.000 \\
\hline 8 & 0 & 0.53 & 0.000 & 0.032 & 0.017 & 0.484 & 0.491 \\
\hline 9 & 3 & 0.53 & 0.073 & 0.031 & 0.017 & 0.000 & 0.000 \\
\hline 10 & 0 & 0.49 & 0.000 & 0.032 & 0.018 & 0.179 & 0.275 \\
\hline 11 & 0 & 0.49 & 0.000 & 0.033 & 0.020 & 0.113 & 0.121 \\
\hline 12 & 2 & 0.49 & 0.053 & 0.036 & 0.022 & 0.137 & 0.206 \\
\hline 13 & 1 & 0.46 & 0.028 & 0.040 & 0.025 & 0.127 & 0.158 \\
\hline 14 & 2 & 0.45 & 0.057 & 0.044 & 0.028 & 0.130 & 0.184 \\
\hline 15 & 1 & 0.42 & 0.030 & 0.049 & 0.033 & 0.128 & 0.168 \\
\hline 16 & 3 & 0.41 & 0.094 & 0.055 & 0.038 & 0.128 & 0.176 \\
\hline 17 & 1 & 0.37 & 0.034 & 0.063 & 0.044 & 0.126 & 0.170 \\
\hline 18 & 3 & 0.36 & 0.107 & 0.071 & 0.050 & 0.125 & 0.171 \\
\hline 19 & 1 & 0.32 & 0.040 & 0.080 & 0.058 & 0.122 & 0.168 \\
\hline 20 & 7 & 0.31 & 0.292 & 0.091 & 0.068 & 0.121 & 0.167 \\
\hline 21 & 2 & 0.22 & 0.118 & 0.102 & 0.078 & 0.118 & 0.165 \\
\hline 22 & 1 & 0.19 & 0.067 & 0.116 & 0.091 & 0.116 & 0.163 \\
\hline 23 & 1 & 0.18 & 0.071 & 0.131 & 0.105 & 0.114 & 0.160 \\
\hline 24 & 1 & 0.17 & 0.077 & 0.148 & 0.121 & 0.111 & 0.158 \\
\hline 25 & 1 & 0.15 & 0.083 & 0.167 & 0.139 & 0.108 & 0.154 \\
\hline 26 & 4 & 0.14 & 0.364 & 0.188 & 0.160 & 0.105 & 0.150 \\
\hline 27 & 1 & 0.09 & 0.143 & 0.211 & 0.184 & 0.101 & 0.146 \\
\hline 28 & 1 & 0.08 & 0.167 & 0.237 & 0.211 & 0.098 & 0.141 \\
\hline 29 & 2 & 0.06 & 0.400 & 0.265 & 0.241 & 0.094 & 0.136 \\
\hline 30 & 0 & 0.04 & 0.000 & 0.296 & 0.274 & 0.089 & 0.130 \\
\hline 31 & 1 & 0.04 & 0.333 & 0.330 & 0.312 & 0.085 & 0.123 \\
\hline 32 & 0 & 0.03 & 0.000 & 0.037 & 0.353 & 0.079 & 0.116 \\
\hline 33 & 1 & 0.03 & 0.500 & 0.406 & 0.397 & 0.074 & 0.108 \\
\hline 34 & 0 & 0.01 & 0.000 & 0.447 & 0.446 & 0.069 & 0.099 \\
\hline 35 & 1 & 0.01 & 1.000 & 0.491 & 0.497 & 0.063 & 0.090 \\
\hline 36 & 0 & & & 0.537 & 0.551 & 0.057 & 0.080 \\
\hline 37 & 0 & & & 0.585 & 0.606 & 0.051 & 0.070 \\
\hline 38 & 0 & & & 0.633 & 0.662 & 0.045 & 0.060 \\
\hline 39 & 0 & & & 0.681 & 0.717 & 0.000 & 0.000 \\
\hline
\end{tabular}


random chance of dying based on its age- and sex-specific survival rate. Birth rates to females were chosen to approximate what is known about bottlenose dolphin birth rates from other populations and were adjusted to give the appropriate rate of population growth. Birth parameters were based on the Barlow and Clapham (1997) birth interval model. All females were assumed to mature and give birth first at age $9 \mathrm{yr}$. The probability of a subsequent birth was zero for the first year after a prior birth and was a constant for each year thereafter. Given this birth rate model, age specific fecundity rates $\left(m_{x}\right)$ (Table 3 ) varied after maturation and generally declined with age (because Leslie-matrix fecundities include the probability of a female surviving to give birth the next year and female survival rates decline with age). Births were assigned randomly as males and females with equal probability. The initial population size, $N$, was chosen to give an expected number of deaths equal to 500-600 over the 20-yr sampling period (simulating the 1978-1997 period during which 491 deaths were observed). The population was initiated in stable age structure and was projected for $10 \mathrm{yr}$ prior to sampling to add some level of stochastic variation in the initial conditions. Dead individuals were sampled randomly to give a total sample size of 125 male dolphins and 78 female dolphins. We fit the Siler survival rate model to the observed age distribution of these samples, separately for males and females. The simulation model was repeated 1,000 times with a different random seed for each iteration. Survivorship $\left(l_{x}\right)$ and mortality rate $\left(q_{x}\right)$ vectors were estimated for each iteration of the model. Standard deviations and $90 \%$ confidence intervals were estimated by treating the simulation results as a standard bootstrap sample. To achieve an exponential growth rate of 0.0 and the observed number of deaths, the constant birth probability was chosen to be 0.37 and the initial population size was 300 ; these parameter combinations resulted in a mean realized growth rate of $0.2 \%$ per year and a mean of 576 deaths over the 20 -yr sampling period. To achieve an exponential growth rate of 0.046 , the constant birth probability was chosen to be 0.56 and the initial population size was 200 ; these parameters resulted in a mean realized growth rate of $4.6 \%$ per year and a mean of 533 deaths over the 20 -yr sampling period.

\section{Non-equilibrium Dynamics and the Effect of Live-captures}

The method we use to estimate age-specific mortality rates from the distributions of ages-at-death assumes that the population has a stable age distribution, which means that age-specific birth and death rates have been constant for a sufficient period of time for the population's age structure to equilibrate. Under these ideal conditions, the fraction of individuals in each age class would not vary from one year to another. Departures from this ideal would be expected given random variations in birth or dearh rates, either from environmental variability or demographic stochasticity in small populations. Most methods of mortality estimation are relatively robust to those types of variation from stable age structure. However, in the case of the Indian River population of bottlenose dolphins, human removals from the population (live captures for public display and research) may have caused systematic deviations from stable age structure and may have biased the estimates of mortality rates. This problem is accentuated because the number of dolphins captured by humans has varied greatly prior to and during the course of our study (Fig. 2) and because the age distribution of the dolphins that were removed (Fig. 3) differs from the expected age distribution of the population. The potential effect of live-capture removals on 


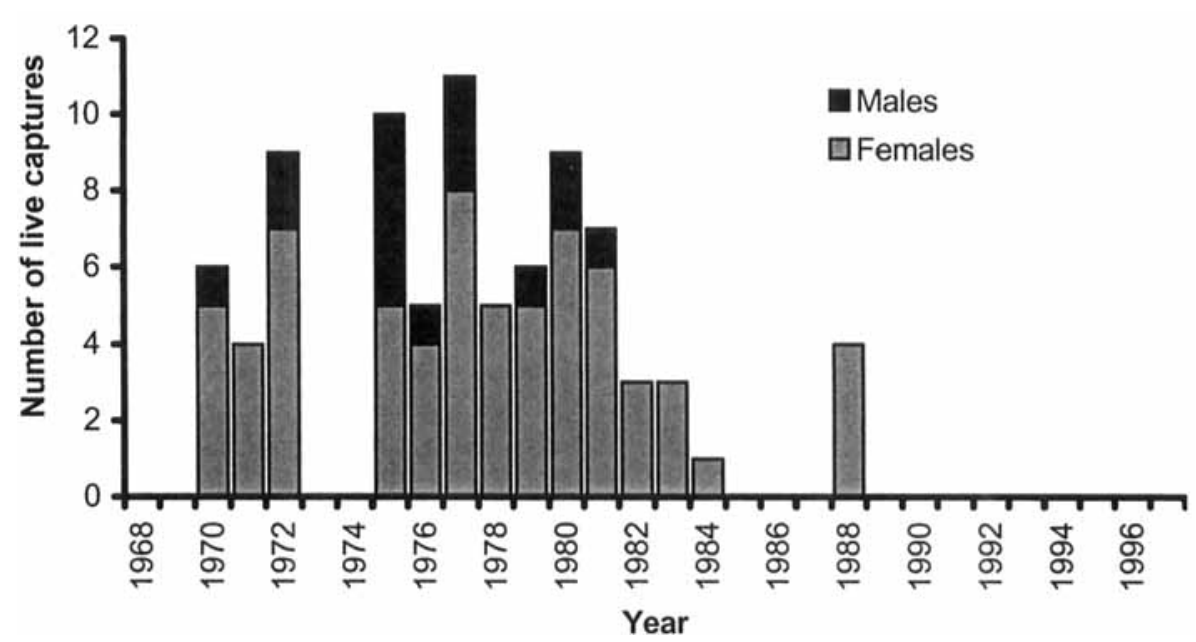

Figure 2. History of live-captures of bottlenose dolphins from the Indian River Lagoon (1968-1997) from records available from National Marine Fisheries Service, Office of Protected Resources, Silver Spring, MD (unpublished data).

mortality rate estimation was explored using a simulation model that included such removals. The magnitude of the effect depends on the actual population size (the numbers that were removed would have a greater effect on a smaller population); however, the size of the Indian River population is not known. Therefore, we explore a worst-case scenario by simulating the dynamics with the smallest reasonable population size. We know that the population must have been large enough to sustain approximately 550 mortalities over the 20 -yr sampling period (based on 491 observed mortalities and an assumed $90 \%$ carcass recovery rate). Given the estimated mortality rates, we estimate that the initial population would have to have been at least 375 individuals (for a stable, non-growing population) or 250 individuals (if the population were growing at $4.7 \%$ per year).

Deviations from stable-age-structure due to human removals (live-capture) were simulated using the same model that was used to estimate sampling variability and demographic stochasticity and included both of those effects. Birth rates were the same as used in the variance simulation. The population was simulated from 1968 to 1997 , which includes $10 \mathrm{yr}$ prior to our sampling period (1978-1997). The only difference was that removals due to live-capture were taken from the population after annual mortality was evaluated for each individual. The number and sex of individuals removed each year were based on the actual history of human removals over this time period (Fig. 2). The age of each individual to be removed was randomly drawn from the actual distribution of estimated age-at-capture (Fig. 3), and if, in a given year, the population did not include an individual of this age, the next youngest individual of the same sex was removed from the population. The simulation was run for 1,000 iterations of this $30-\mathrm{yr}$ population projection. The sample of "observed" known-aged mortalities (78 females and 125 males) was chosen randomly from the mortalities that were registered during the last $20 \mathrm{yr}$ of each simulation, and mortality rates were estimated after each iteration using the maximum likelihood Siler model. Individuals that were removed from the population to simulate live capture were not used in the mortality estimation. 


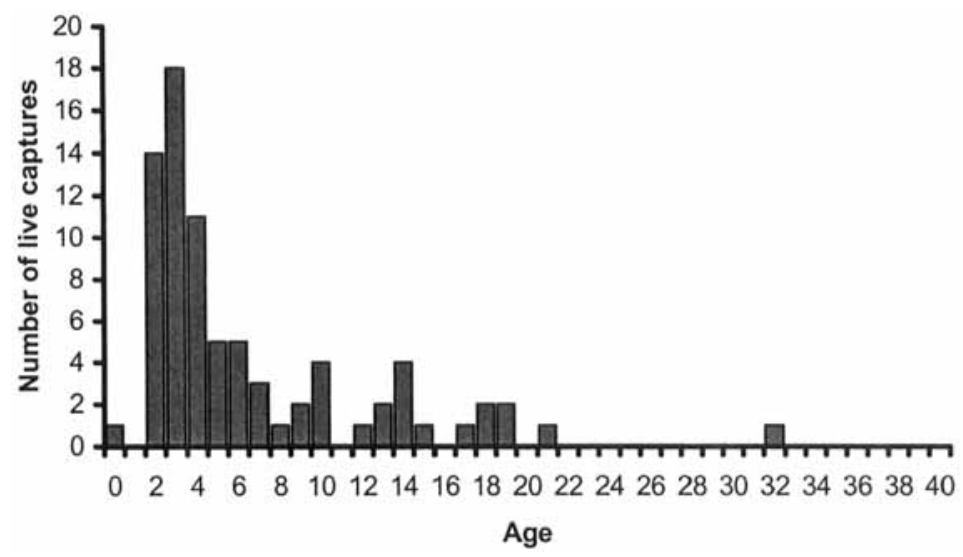

Figure 3. Age structure of bottlenose dolphins removed from Indian River Lagoon at the time of live-capture (age data available from a number of sources including National Marine Fisheries Service, Silver Spring, MD as provided by collection source, ages estimated from length data, and other reference data from collection source).

The mean mortality rate with simulated live-capture removals was estimated as the mean (for each age class) of the 1,000 simulations.

\section{RESULTS}

A total of 491 dolphins were found stranded in the study area from 1978 to 1997. Of the 220 dolphins for which teeth were available for age estimation (Table 1), 125 were male, 78 female, and 17 were of unknown sex. The oldest male and female were each $35 \mathrm{yr}$ of age. There were no other males over $27 \mathrm{yr}$ (Table 2). Few females were found dead between the ages of 6 and $11 \mathrm{yr}$ (Table 3).

Life table analysis and subsequent survival and mortality curves showed distinct differences in the age- and sex-specific survival and mortality rates for the IRL dolphin population. Both sexes showed relatively high rates of mortality among young animals $(<5 \mathrm{yr})$ with mortality rates decreasing and remaining fairly low until age 15 . Using data from our life table, we estimate that the overall mortality rate for the IRL dolphin population is approximately $9.8 \%$ per year.

The number of strandings per year increased at an exponential rate of 0.046 (or approximately $4.7 \%$ per year) over the period of 1978-1997 (Fig. 4). Three years $(1982,1996$, and 1997) appeared to be outliers. The first of these years was associated with a possible outbreak of morbillivirus (Duignan et al. 1996). There is still no explanation for the higher stranding rates in 1996-1997. Excluding those three potential outliers, the exponential growth rate was only slightly different (0.042), so the growth rate from the entire time series was used in estimating mortality rates. If the population was growing, as indicated by these data, then the age structure would be shifted towards younger ages, and mortality rates would be overestimated by traditional methods that assume zero growth (Table 1-3).

Smoothed survivorship and mortality rates were estimated using two assumed population growth rates $r=0.046$ and $r=0.000$ ). Sex-specific differences in survivorship were apparent using either assumed population growth rate (Fig. 5). The mortality rates for males and females showed similar patterns (Fig. 6, 7). Differences 


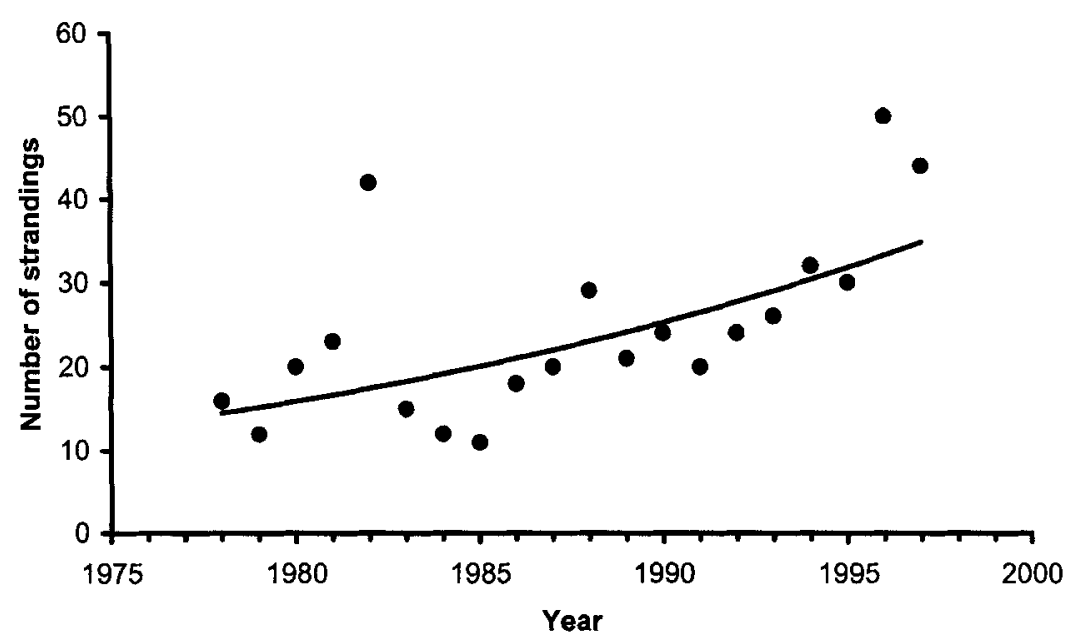

Figure 4. Number of bottlenose dolphin strandings per year reported in the Indian River Lagoon system from 1978 to 1997 . Solid line represents the log-linear regression fit to these data that was used to estimate the exponential rate of population growth $(r=0.046)$.

in assumed population growth rate affected the magnitude of the mortality rates, but did not change the overall age- or sex-specific patterns.

Uncertainty in estimates of age-specific mortality rates due to sampling variability and demographic stochasticity was estimated using an individual-based simulation model and is expressed as $90 \%$ confidence intervals around the estimated rates (Fig. 8). These results show that survival rate estimates are relatively precise in the range of $5-15$ yr $(\mathrm{CVs} \approx 1.2 \%)$, are somewhat less accurate for younger ages, and have considerable uncertainty above $20 \mathrm{yr}$ of age. Departures from stable-agedistribution were investigated using a simulation of known human removals from the population (live capture), and, in the worst-case scenario, biases were generally small and fell within the range of sampling variation (Fig. 8). The effect of live captures was greater in females (which included most of the live captures) and was greater in the first two age classes. Human removals were found to decrease the realized population growth rate by approximately $2 \%$ in this simulation, but the effect would be smaller if the population were larger than those sizes used in this worst-case scenario.

\section{DisCUSSION}

Age-specific and Sex-specific Mortality Patterns

The overall survival curve for IRL dolphins is similar to survival curves observed in studies of some terrestrial mammals (Spinage 1972). This "Type I" (Pearl and Miner 1935) curve is typical of mammals and other long-lived species. The sex-specific survival curves show that males have lower survival rates than females at all ages, with a larger difference occurring around the age of 15 yr. Likewise, mortality curves created from these life table data resemble the typical U-shaped curves of other large mammals (Caughley 1966, Spinage 1972, Sinclair 1977). Again, there are differences between the sexes with males showing higher mortality at all age classes. 


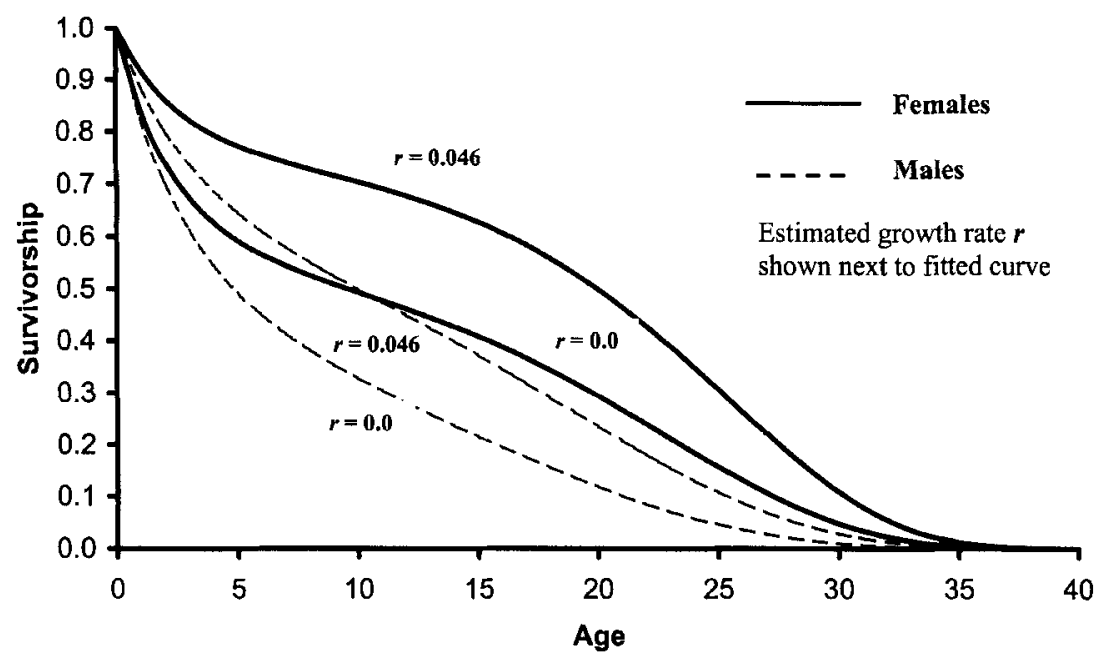

Figure 5. Age-specific survivorships $\left(l_{x}\right)$ for female and male bottlenose dolphins based on maximum likelihood fits of the Siler model (Table 4). Upper curves represent survivorship with the estimated growth rate of 0.046 ; lower curves represent survivorship with an assumed growth rate of 0.0 .

These large differences in age- and sex-specific mortality are not uncommon for mammals. Higher mortality among the very young has been shown in both terrestrial (Caughley 1966) and marine mammals. High neonate mortality has been shown for pinnipeds (Chapman 1964) and cetaceans such as Atlantic spotted dolphins, Stenella frontalis (Herzing 1997). In Tursiops, high neonate and calf mortality has been shown in Texas (Fernandez 1992) and Sarasota, Florida (Wells and Scott 1990), and in captive populations (Small and DeMaster 1995). In Sarasota, Wells and Scott (1990) estimated that the mortality rate of all animals older than one year was between 0.010 and 0.038 and that minimum mortality rate for young of the year was 0.189 .

We would expect that the actual number of calves dying in the population may exceed the number of carcasses found by stranding personnel due to the more rapid decomposition, greater vulnerability to predation, and lower detection probability of small-sized animals. However, the frequency of calves from our life table (8.36\%) is consistent with published studies where IRL calving data were estimated (Leatherwood 1979, see reviews in Leatherwood and Reeves 1982 and Perrin and Reilly 1984). The enclosed geography of the Indian River Lagoon system makes carcass recovery more likely than on exposed beaches of the Atlantic and dedicated effort by stranding personnel has been consistent for many years.

Causes of high calf mortality are difficult to tease apart. Like other mammals, the answers probably lie in confounding effects of nutrition, social interactions, and predation pressures. Cockcroft et al. (1989) suggested that young dolphins, especially first-born calves, carry the burden of contaminants passed on from their mothers through nursing. This effect, as well as other health-related stresses, may put young dolphins at greater risk of disease and death. Other possible causes of higher mortality may be related to the behavior and social structure of dolphins. Dolphin calves remain with their mothers until the age of three to six years (Wells 
Table 4. Maximum likelihood estimates of the Siler model (Eq. 1) fit to the mortality data for males and females based on two assumed rates of population growth. Uncertainty in parameter estimates cannot be expressed with standard errors because parameters are highly correlated; uncertainty is best visualized as the $90 \%$ confidence intervals around the fitted line (Fig. 8).

\begin{tabular}{ccccccc}
\hline \hline & & \multicolumn{5}{c}{ Siler parameters } \\
\cline { 3 - 7 } Sex & Growth rate & $a_{1}$ & $a_{2}$ & $a_{3}$ & $b_{1}$ & $b_{3}$ \\
\hline Females & 0.000 & 0.1937 & 0.0000 & 0.0064 & 0.3237 & 0.1310 \\
& 0.046 & 0.0960 & 0.0000 & 0.0031 & 0.3317 & 0.1523 \\
Males & 0.000 & 0.1914 & 0.0000 & 0.0209 & 0.2249 & 0.0978 \\
& 0.046 & 0.1201 & 0.0000 & 0.0129 & 0.2363 & 0.1103 \\
\hline
\end{tabular}

et al. 1987), but physically separate from their mothers for short intervals as weaning age approaches (Shane 1990). During this time, young dolphins may be more susceptible to predatory attacks by sharks (Wells 1991, Herzing 1997) and injury caused by other dolphins. Likewise, this separation may result in greater risk to young dolphins from harmful human interactions such as boat strikes (Wells and Scott 1997). From the traditional method of calculating life tables, we found an unusually high rate of mortality between two and three years of age, presumably the time of weaning in IRL bottlenose dolphins (Tavolga and Essapian 1957). The inability of newly weaned calves to properly forage or protect themselves against predators or injury caused by other dolphins may have a profound effect on the overall calf mortality rate.

Our data show that male dolphins in the IRL experience higher mortality than females at a given age. Higher rates of male mortality have been shown in other bottlenose dolphin populations (Fernandez 1992, Scott et al. 1990, Fernandez and Hohn 1998). There are probably several factors that contribute to this finding. Again, dolphin social structure may be involved. In Sarasota Bay, both males and females form juvenile groups after separation from their mothers, but the females rejoin the larger, and presumably more protective, female bands, while the males often travel in pairs (Wells et al. 1987). Differences in ranging patterns may also increase male susceptibility to predation. For instance, males traveling alone or using open water or areas near inlets for travel corridors may be more vulnerable to predatory sharks. If IRL males emigrate and enter neighboring dolphin communities as they do in Sarasota, male-male competition could result in both direct and indirect mortality. This has been shown in other mammal species (Ralls et al. 1980). We note, however, that mortality occurring outside the lagoon system will be reflected only indirectly in our age-at-death data from inside the lagoon. While these factors may be involved, additional physiological and metabolic influences certainly contribute to the higher male mortality rate as well. In most cases, cause of death was not apparent during necropsies of IRL dolphins.

Although we found higher mortality rates for males, which was expected, we also found a skewed sex ratio among all stranded dolphins within the IRL (125 M:78 F). If the sex ratio at birch is parity, we would have expected to see equal numbers of male and female strandings. The reason for this difference from parity is not known. However, assuming a one-to-one ratio at birth, the most parsimonious explanation may lie in possible movements of males into the system or females moving out of 


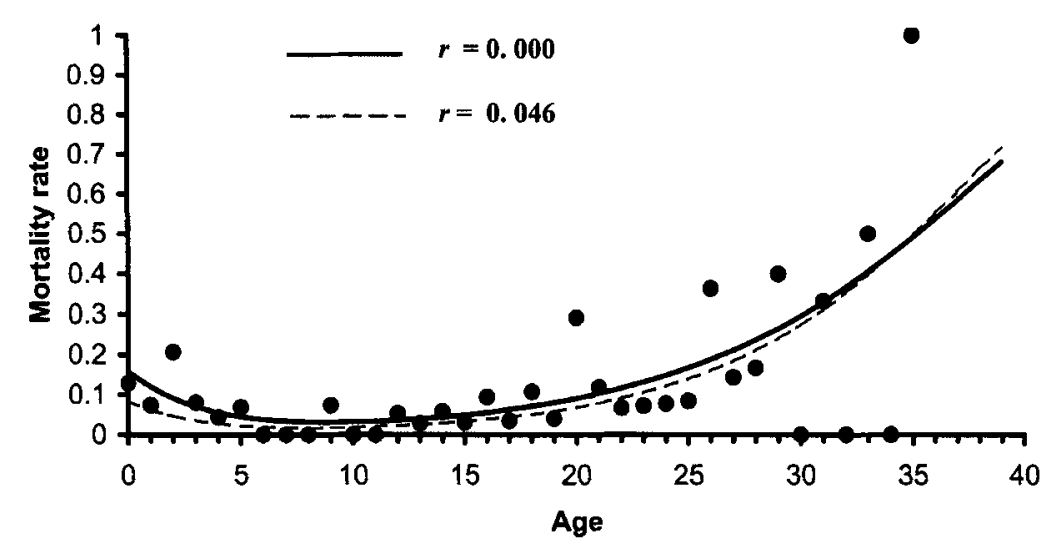

Figure 6. Age-specific mortality rates $\left(q_{x}\right)$ for female bottlenose dolphins. Points $(\bullet)$ are from traditional life table calculations (Table 3 ) and assume that population growth is zero. Smoothed curves are based on a maximum likelihood fit to the Siler model with population growth rates of 0.0 and 0.046 .

the system. Male dolphins have been shown to have wider ranging patterns than females in some parts of their range (Scott et al. 1990). If males move into the IRL from adjacent oceanic waters, a biased sex ratio within IRL boundaries may result. More behavioral data, health assessment data, and pathological investigations are needed for the IRL dolphin population before this sex-related mortality difference can be explained.

\section{Population Growth Rate}

Although the age- and sex-specific patterns of mortality in this population are not dependent on the assumed rate of population growth, the absolute magnitudes of the mortality rates are. This is illustrated best in the plots of age-specific survivorship (Fig. 5). The growth rate estimated from the increase in number of strandings $(r=0.046)$ is near the maximum rate that might be expected for a delphinid (Reilly and Barlow 1986). Population growth has not been directly measured for this or other eastern Florida populations; however, a well-studied bottlenose dolphin population in a lagoon system on the west coast of Florida (Sarasota Bay) has been stable during the same time period (Wells and Scott 1999).

It is unclear what effect humans have had on the population structure of dolphins in the IRL, but several factors should be considered. In 1995 Florida banned the use of commercial fishing nets within nearshore waters. These nets had been blamed for some of the dolphin mortality in the IRL, however, data on actual net-related injury and death have been difficult to gather (Stolen, unpublished data). Other humancaused dolphin mortality in the IRL, especially indirect effects of pollution, has not been addressed. Overall, data are insufficient to determine what effect, if any, human-caused mortality factors may have had on the overall growth rate of the IRL dolphin population. The use of trends in strandings as an index of population change is questionable, because there may be trends in the frequency with which strandings are reported or changes in mortality rates over time. We cannot say with 


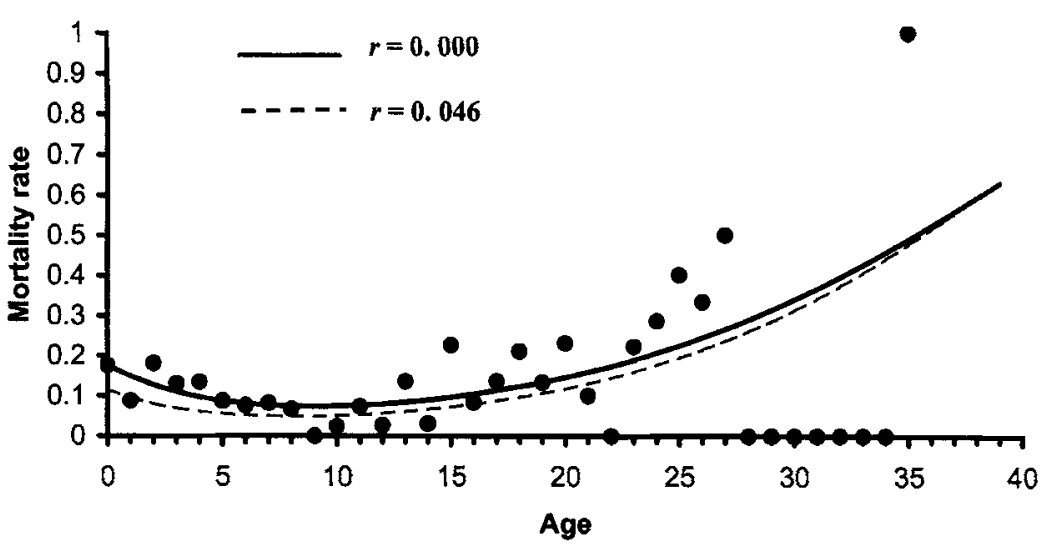

Figure 7. Age-specific mortality rates $\left(q_{x}\right)$ for male bottlenose dolphins. Points $(\bullet)$ are from traditional life table calculations (Table 2) and assume that population growth is zero. Smoothed curves are based on a maximum likelihood fit to the Siler model with population growth rates of 0.0 and 0.046 .

assurance that the population is increasing at $4.7 \%$ per year. However, the population growth rate during this time period was most likely bracketed between the two values we used $(0.0$ to $4.7 \%$ per year $)$.

\section{Stable Age Distribution}

Methods of estimating mortality rates from ages-at-death require that the population be in stable age distribution (Caughley 1966). This assumption is difficult to validate; however, long-lived species, like dolphins, are buffered from perturbations from stable age distribution by virtue of their long reproductive period and high survival rates. Furthermore, our data on age-at-death are based on a 20 -yr time series that also acts to average out the deviations that might be present in any single year. For these reasons, we believe our data are representative of a population in stable age distribution and our methods are robust to likely deviations from stable age distribution caused by live-capture removals.

\section{Longevity}

Our survivorship curves (Fig. 5) show that few females live past $35 \mathrm{yr}$ and few males live past $30 \mathrm{yr}$. This is approximately 10-17 yr less than the maximum longevity observed in male and female bottlenose dolphins in Sarasota Bay, Florida (Wells and Scott 1999) based on 91 animals in the population of 99. This difference in overall longevity could be explained in three ways: (1) there was error in age estimation for IRL dolphins resulting in an underestimate of the true age of the stranded animals, (2) older animals "exist" in the population but their carcasses were not recovered or aged, or (3) there are population-level differences in longevity between the IRL and Sarasota Bay dolphins.

We believe that the ages of the animals estimated from stained, thin sections were accurate. Standard methods were used and ages were read using the methods 

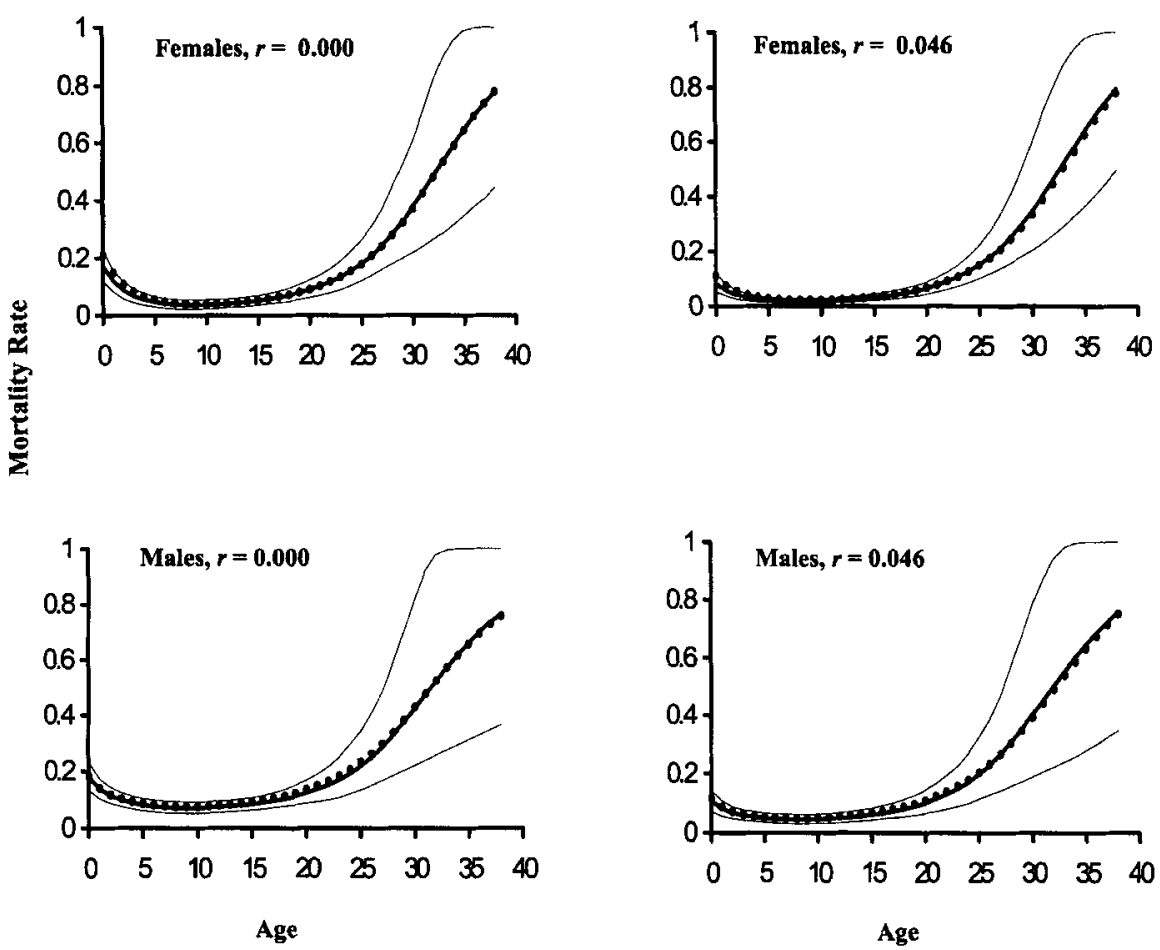

Figure 8. Mean estimated mortality rates (bold line) and $90 \%$ confidence limits (fine lines) for bottlenose dolphins in Indian River Lagoon given two assumed rates of population growth. Dots indicated mean estimated survival rates from a simulation model that includes live-capture removals from the population (see text).

of Hohn et al. (1989). Growth rates, based on this same age-estimated sample, were consistent with previous studies on Tursiops growth (Stolen et al. 2002). The possibility that some older animals were unrecovered is probably low due to the effort by personnel in the area and the enclosed geography of the IRL. However, while carcass recovery was high, teeth were not always collected to determine age. It is therefore possible that some older animals were "lost" in the process. While this factor cannot be ignored, we believe that our study is based on an adequate sample that reflects the true age distribution of the IRL population.

Several studies are currently being conducted on this dolphin population, as many questions about the overall health of the IRI system and its inhabitants are under increased scrutiny by management and conservation organizations. Our study provides the first comprehensive IRL dolphin population assessment over a 20 -yr period and provides valuable baseline data for on-going research. Our approach using this model is also broadly applicable to data gathered by stranding network participants throughout the US and in other areas with consistent carcass recovery. With dedicated collection of life history samples (teeth and reproductive organs), similar age-structured models could be developed for other populations of marine mammals. 


\section{ACKNOWLEDGMENTS}

We thank members of the Southeastern United States Marine Mammal Stranding Network for data and tooth sample collection. Data on captures in the Indian River Lagoon were provided by National Marine Fisheries Service, Office of Protected Resources, Silver Spring, Maryland, USA. Thesis work by MKS was supervised by Franklin Snelson, Nélio Barros, Llewellyn Ehrhart, Daniel Odell, and Jack Stout. MKS thanks Eric Stolen for guidance throughout the project. Earlier versions of the manuscript were improved by comments from Peter Boveng, Dan Goodman, and Michael Scott. The submitted manuscript was greatly improved by the editor and two anonymous reviewers. Funding for MKS was provided by Hubbs-Sea World Research Institute and Sea World, Inc.

\section{Literature Cited}

Aguilar, A., And J. A. Raga, 1993. The striped dolphin epizootic in the Mediterranean Sea. Ambio 22:524-528.

BARLOW, J., AND P. BOVENG. 1991. Modeling age-specific mortality of marine mammal populations. Marine Mammal Science 7:50-65.

Barlow, J., AND P. J. Clapham. 1997. A new birth-interval approach to estimating demographic parameters of humpback whales. Ecology 78:535-546.

Bodkin, J. L., A. M. Burdin, AND D. A. RYAzAnov. 2000. Age- and sex-specific mortality and population structure in sea otters. Marine Mammal Science 16:201-219.

Brautt, S., AND H. CAswell. 1993. Pod-specific demography of killer whales (Orcinus orca). Ecology 74:1444-1454.

CAUGHLey, G. 1966. Mortality patterns in mammals. Ecology 47:906-918.

Chapman, D. G. 1964. A critical study of Pribilof fur seal population estimates. Fishery Bulletin, U.S. 63:657-669.

Clinton, W. L., AND B. J. Le Boeuf. 1993. Sexual selection's effects on male life history and the pattern of male mortality. Ecology 74:1884-1892.

Cockcroft, V. G., A. C. DeKock, G. J. B. Ross And D. A. Lord. 1989. Organochlorines in bottlenose dolphins from the east coast of southern Africa. South African Journal of Marine Science 8:207-217.

Crouse, D. T., L. B. Crowder and H. Caswell. 1987. A stage-based population model for loggerhead sea turtles and implications for conservation. Ecology 68:1412-1423.

Doak, D. F., P. M. Kareiva AND B. KiepetKa. 1994. Modeling population viability for the desert tortoise in the western Mojave Desert. Ecological Applications 3:446-460.

Duignan, P. J., C. House, D. K. Odeli, R. S. Wells, L. J. Hansen, M. T. Walsh, D. J. St. Aubin, B. K. Rima and J. R. Geraci. 1996. Morbillivirus infection in bottlenose dolphins: Evidence for recurrent epizootics in the western Atlantic and Gulf of Mexico. Marine Mammal Science 12:499-515.

Fernandez, S. P. 1992. Composición de edad y sexo y parametros del ciclo de vida de toninas (Tursiops truncatus) varadas en el noroeste del Golfo de Mexico. Master's thesis. Instituto Technologico de Estudios Superiores de Monterrey, Guaymas. 109 pp.

Fernandez, S. P., AND A. A. Hohn. 1998. Age, growth, and calving season of bottlenose dolphins, Tursiops truncatus, off coastal Texas. Fishery Bulletin, U.S. 96:357-365.

GaGe, T. B., AND B. Dyke. 1988. Model life tables for the larger Old World monkeys. American Journal of Primatology 16:305-320.

Hersh, S. L., D. K. Odell AND E. D. Asper. 1990. Bottlenose dolphin mortality patterns in the Indian/Banana River system of Florida. Pages 155-164 in S. Leatherwood and R. R. Reeves, eds. The bottlenose dolphin. Academic Press, Inc., San Diego, CA.

Herzing, D. L. 1997. The life history of free-ranging Atlantic spotted dolphins (Stenella frontalis): Age classes, color phases, and female reproduction. Marine Mammal Science $13: 576-595$. 
Hewer, H. R. 1964. The determination of age, sexual maturity, longevity and a life table in the grey seal (Halichoerus grypus). Proceedings of the Zoological Society of London 142:593-624.

Hohn, A. A., M. D. Scott, R. S. Wells, J. C. Sweeney and A. B. Irvine. 1989. Growth layers in teeth from known-age, free-ranging bottlenose dolphins. Marine Mammal Science 3:315-342.

Krebs, C. J. 1989. Ecological methodology. Harper Collins Publishers, New York, NY.

LAWs, R. M. 1968. Dentition and ageing of the hippopotamus. East African Wildlife Journal 6:19-52.

LEATHERWOOD, S. 1979. Aerial survey of the bottlenosed dolphin, Tursiops truncatus, and the West Indian manatee, Trichecbus manatus, in the Indian and Banana Rivers, Florida. Fishery Bulletin, U.S. 77:47-59.

LeATHERWOOD. S., AND R. R. ReEves. 1982. Bottlenose dolphin, Tursiops truncatus, and other toothed cetaceans. Pages 369-414 in J. A. Chapman and G. A. Feldhamer, eds. Wild mammals of North America, biology, management, and economics. John Hopkins University Press, Baltimore and London.

Marmontel, M. 1993. Age determination and population biology of the Florida manatee, Trichecbus manatus latirostris. Doctoral dissertation, University of Florida, Gainesville, FL. 408 pp.

Marmontel, M., S. R. Humphrey and T. J. O'Shea. 1997. Population viability analysis of the Florida manatee (Trichechus manatus latirostris), 1976-1991. Conservation Biology $11: 467-481$.

Myrick, A. C., A. A. Hohn, P. A. Sloan, M. Kimura and D. D. Stanley. 1983. Estimating age of spotted and spinner dolphins (Stenella attenuata and Stenella longirostris) from teeth. NOAA technical memorandum. Southwest Fisheries Center, National Marine Fisheries Service. Report number NOAA-TM-NMFS-SWFC-30. La Jolla, CA. 17 pp.

Nieri, M., E. Grad, B. Lamarche and A. Aguliar. 1999. Mass mortality of Atlantic spotted dolphins (Stenella frontalis) caused by a fishing interaction in Mauritania. Marine Mammal Science 15:847-854.

Odeli, D. K., AND E. D. Asper. 1990. Distribution and movements of freeze-branded bottlenose dolphins in the Indian and Banana Rivers, Florida. Pages 515-540 in S. Leatherwood and R. R. Reeves, eds. The bottlenose dolphin. Academic Press, Inc., San Diego, CA.

Olesiuk, P. F., M. A. BIGG AND G. M. Ellis. 1990. Life history and population dynamics of resident killer whales (Orinus orca) in the coastal waters of British Columbia and Washington State. Reports of the International Whaling Commission (Special Issue 12): 209-243.

Pearl, R., and J. R. Miner. 1935. Experimental studies on the duration of life. XIV. The comparative mortality of certain lower organisms. Quarterly Review of Biology 10:60-79.

Perrin, W. F., AND A. C. MYrick, EDs. 1980. Age determination of toothed whales and sirenians. Report of the International Whaling Commission (Special Issue 3).

Perrin, W. F., AND S. B. Reilly. 1984. Reproductive parameters of dolphins and small whales of the family Delphinidae. Report of the International Whaling Commission (Special Issue 6):97-133.

Press, W. H., B. P. Flannery, S. A. Teukolsky and W. T. Vetrerling. 1988. Numerical Recipes: The art of scientific computing. Cambridge University Press, Cambridge.

Ralls, K., R. L. Brownell, Jr. AND J. Bat.ou. 1980. Differential mortality by sex and age in mammals, with specific reference to the sperm whale. Report of the International Whaling Commission (Special Issue 2):233-243.

ReILIY, S. B., AND J. BARLOW. 1986. Rates of increase in dolphin population size. Fishery Bulletin, U.S. 84:527-533.

Scort, G. P. 1990. Management-oriented research on bottlenose dolphins by the Southeast Fisheries Center. Pages 623-639 in S. Leatherwood and R. R. Reeves, eds. The bottlenose dolphin. Academic Press, Inc., San Diego, CA. 
ScotT, M. D., R. S. WELts AND A. B. IRvine. 1990. A long-term study of bottlenose dolphins on the west coast of Florida. Pages 235-244 in S. Leatherwood and R. R. Reeves, eds. The bottlenose dolphin. Academic Press, Inc., San Diego, CA.

Sergeant, D. E., D. K. Caldwell and M. C. Caldwell. 1973. Age, growth, and maturity of bottlenosed dolphin (Tursiops truncatus) from northeast Florida. Journal of the Fisheries Research Board of Canada 30:1009-1011.

Shane, S. H. 1990. Behavior and ecology of the bottlenose dolphin at Sanibel Island, Florida. Pages 245-265 in S. Leatherwood and R. R. Reeves, eds. The bottlenose dolphin. Academic Press, Inc., San Diego, CA.

SILER, W. 1979. A competing risk model for animal mortality. Ecology 60:750-757.

SinCLAIR, A. R. E. 1977. The African buffalo: A study of resource limitation of populations. The University of Chicago Press, Chicago and London.

SinIFF, D. B., AND K. Ralis. 1991. Reproduction, survival, and tag loss in California sea otters. Marine Mammal Science 7:211-229.

Smail, R. J., AND D. P. DeMaster. 1995. Survival of five species of captive marine mammals. Marine Mammal Science 11:209--226.

Spinage, C. A. 1972. African ungulate life tables. Ecology 53:645-652.

STOLEN, M. K. 1998. Age, growth, and mortality of bottlenose dolphins from the east coast of Florida. Master's thesis, University of Central Florida, Orlando, FL. 153 pp.

Stolen, M. K., D. K. Odell AND N. B. Barros. 2002. Growth of bottlenose dolphins (Tursiops truncatus) from the Indian River Lagoon system, Florida, USA. Marine Mammal Science 18:348-357.

Tavolga, M. C., AND F. S. Essapian. 1957. The behavior of the bottle-nosed dolphin (Tursiops truncatus): Mating, pregnancy, parturition, and mother-infant behavior. Zoologica 42(2): 11-31.

Vidal, O., AND J. Gallo-Reynoso. 1996. Die-offs of marine mammals and sea birds in the Gulf of California, Mexico. Marine Mammal Science 12:627-635.

WeLLS, R. S. 1991. Bringing up baby. Natural History. 8/91:56-62.

WELIS, R. S., AND M. D. SCOTT. 1990. Estimating bottlenose dolphin population parameters from individual identification and capture-release techniques. Reports of the International Whaling Commission (Special Issue 12):407-415.

Wells, R. S., AND M. D. ScotT. 1997. Seasonal incidence of boat strikes on bottlenose dolphins near Sarasota, Florida. Marine Mammal Science 13:475-480.

Wells, R. S., AND M. D. SCOTT. 1999. Bottlenose dolphin (Tursiops truncatus). Pages 137 182 in S. H. Ridgway and R. Harrison, eds. Handbook of marine mammals. Volume 6. The second book of dolphins. Academic Press, Inc., San Diego and London.

Wells, R. S., M. D. ScotT AND A. B. IRvine. 1987. The social structure of free-ranging bottlenose dolphins. Pages 247-305 in H. H. Genoways, ed. Current mammalogy. Plenum Press, NY.

Received: 2 June 2002

Accepted: 2 February 2003 